\title{
Functional Evidence for a Cerebellar Node of the Dorsal Attention Network
}

\author{
James A. Brissenden, ${ }^{1 \star}$ Emily J. Levin, ${ }^{1 \star}$ David E. Osher, ${ }^{1}{ }^{\oplus}$ Mark A. Halko, ${ }^{2}$ and ${ }^{\oplus D a v i d ~ C . ~ S o m e r s ~}{ }^{1}$ \\ ${ }^{1}$ Department of Psychological and Brain Sciences, Boston University, Boston, Massachusetts 02215, and ${ }^{2}$ Berenson-Allen Center for Noninvasive Brain \\ Stimulation, Beth Israel Deaconess Medical Center, Boston, Massachusetts 02215
}

The "dorsal attention network" or "frontoparietal network" refers to a network of cortical regions that support sustained attention and working memory. Recent work has demonstrated that cortical nodes of the dorsal attention network possess intrinsic functional connections with a region in ventral cerebellum, in the vicinity of lobules VII/VIII. Here, we performed a series of task-based and resting-state fMRI experiments to investigate cerebellar participation in the dorsal attention network in humans. We observed that visual working memory and visual attention tasks robustly recruit cerebellar lobules VIIb and VIIIa, in addition to canonical cortical dorsal attention network regions. Across the cerebellum, resting-state functional connectivity with the cortical dorsal attention network strongly predicted the level of activation produced by attention and working memory tasks. Critically, cerebellar voxels that were most strongly connected with the dorsal attention network selectively exhibited load-dependent activity, a hallmark of the neural structures that support visual working memory. Finally, we examined intrinsic functional connectivity between task-responsive portions of cerebellar lobules VIIb/VIIIa and cortex. Cerebellum-to-cortex functional connectivity strongly predicted the pattern of cortical activation during task performance. Moreover, resting-state connectivity patterns revealed that cerebellar lobules VIIb/VIIIa group with cortical nodes of the dorsal attention network. This evidence leads us to conclude that the conceptualization of the dorsal attention network should be expanded to include cerebellar lobules VIIb/VIIIa.

Key words: cerebellum; dorsal attention network; fMRI; visual attention; visual working memory

\section{Significance Statement}

The functional participation of cerebellar structures in nonmotor cortical networks remains poorly understood and is highly understudied, despite the fact that the cerebellum possesses many more neurons than the cerebral cortex. Although visual attention paradigms have been reported to activate cerebellum, many researchers have largely dismissed the possibility of a cerebellar contribution to attention in favor of a motor explanation, namely, eye movements. The present study demonstrates that a cerebellar subdivision (mainly lobules VIIb/VIIIa), which exhibits strong intrinsic functional connectivity with the cortical dorsal attention network, also closely mirrors a myriad of cortical dorsal attention network responses to visual attention and working memory tasks. This evidence strongly supports a reconceptualization of the dorsal attention network to include cerebellar lobules VIIb/VIIIa.

\section{Introduction}

Attention influences neural structures throughout the brain but is controlled by a more limited architecture (e.g., Kastner and

Received Jan. 31, 2016; revised April 1, 2016; accepted April 27, 2016.

Author contributions: J.A.B., M.A.H., and D.C.S. designed research; J.A.B. and E.J.L. performed research; J.A.B., E.J.L., and D.E.O. analyzed data; J.A.B., E.J.L., M.A.H., and D.C.S. wrote the paper.

This work was supported by the National Institutes of Health Grant R01EY022229 to D.C.S., National Science Foundation Graduate Research Fellowship DGE-1247312 to J.A.B., and the Sidney R. Baer Jr. Foundation to M.A.H. We thank Thomas Benner and Himanshu Bhat (Siemens Medical Solutions) and Steven Cauley (Massachusetts General Hospital) for modifying and supplying the simultaneous multislice-BOLD imaging sequence used in this work; Timothy A. Brown (Boston University) for helpful discussions concerning statistical methods; Kathryn Devaney for revisions to stimulus presentation code; and Maya Rosen for assistance with data collection.

The authors declare no competing financial interests.

*J.A.B. and E.J.L. contributed equally to this work.
Ungerleider, 2000). Our understanding of the brain structures that control attention has evolved from a unitary parietal locus (Critchley, 1953), to a frontoparietal network (e.g., Mesulam, 1981; Posner and Petersen, 1990), to multiple networks (e.g., Corbetta and Shulman, 2002; Dosenbach et al., 2007; Yeo et al., 2011; Michalka et al., 2015; Rosen et al., 2015). Today, there is widespread agreement that a "dorsal attention network" (DAN) or "frontoparietal network" directs visual attention and shortterm memory processes (e.g., Courtney et al., 1998; Hagler and

Correspondence should be addressed to Dr. David C. Somers, 64 Cummington Mall, Boston, MA 02215. E-mail: somers@bu.edu.

DOI:10.1523/JNEUROSCI.0344-16.2016

Copyright $\odot 2016$ the authors $\quad 0270-6474 / 16 / 366083-14 \$ 15.00 / 0$ 
Sereno, 2006; Szczepanski et al., 2010; Ikkai and Curtis, 2011; Sprague and Serences, 2013). Moreover, this network is distinct from a cingulo-opercular cognitive control network (CCN) (Dosenbach et al., 2007; Power et al., 2011; Yeo et al., 2011). Yet, no consensus has been reached regarding the precise components of the DAN. On the basis of task-based and resting-state fMRI studies, the DAN in humans is typically defined to include all or some of the following four regions: (1) intraparietal sulcus (IPS)/ superior parietal lobule; (2) superior pre-central sulcus (sPCS) containing the homolog of primate frontal eye fields; (3) inferior pre-central sulcus (iPCS), alternately known as inferior frontal junction; and (4) the motion-sensitive area MT complex $\left(\mathrm{MT}^{+}\right)$ (Fox et al., 2005; Szczepanski et al., 2010; Power et al., 2011; Ptak and Schnider, 2011; Yeo et al., 2011; Gao and Lin, 2012). Whereas subcortical structures, such as superior colliculus and pulvinar, are often implicated in attentional functions (e.g., Goldberg and Wurtz, 1972; Saalmann et al., 2012), cerebellar structures are not typically discussed among the neural substrates of attention.

Prior work has demonstrated cerebellar activation during working memory and attention tasks (Allen et al., 1997; Desmond et al., 1997; Le et al., 1998; O’Reilly et al., 2008; Salmi et al., 2010; Kellermann et al., 2012; Stoodley et al., 2012). However, the role of the cerebellum in cognition has long been dismissed (e.g., Glickstein, 2007), and some suggest that cerebellar activation may be a vestige of the evolution of the mammalian brain with little involvement in cognitive processes (Buckner, 2013). Interestingly, both polysynaptic tracing (Kelly and Strick, 2003) and corticocerebellar intrinsic functional connectivity studies (Buckner et al., 2011) indicate that the cerebellum is not a unitary structure. Multiple higher-order association networks share intrinsic functional connectivity with distinct cerebellar regions, including the DAN and default mode network (DMN) (Habas et al., 2009; Krienen and Buckner, 2009; O'Reilly et al., 2010; Buckner et al., 2011). Specifically, Buckner et al. (2011) identified a region spanning cerebellar lobules VIIb and VIIIa that exhibits connectivity with the cortical DAN and a region within the lateral-most portion of Crus I and II that couples with the cortical DMN. In cortex, the DAN and DMN competitively interact, such that the DAN is activated and the DMN is suppressed during cognitive task performance (Shulman et al., 1997; Gusnard et al., 2001; Corbetta and Shulman, 2002). Furthermore, recruitment of the DAN reflects the number of items maintained in working memory (Todd and Marois, 2004; Vogel and Machizawa, 2004; Xu and Chun, 2006; Sheremata et al., 2010). It remains unclear whether cerebellar regions coupled with the DAN and DMN exhibit similar patterns of activation and interaction as their cortical counterparts.

Here, using fMRI, we observe that corticocerebellar connectivity predicts cerebellar activation in individual subjects during visual attention and visual working memory (VWM) task performance. Cerebellar lobules VIIb/VIIIa not only exhibit strong intrinsic functional connectivity with the cortical DAN, but their task-driven responses mirror those of the cortical DAN. These findings strongly support the view that the DAN functionally extends to a portion of the cerebellum.

\section{Materials and Methods}

Subjects. Fourteen healthy subjects (eight female) participated in these experiments. All subjects were compensated and gave written informed consent to participate in the study, which was approved by the Institutional Review Board of Boston University. Subjects were recruited from Boston University and the Greater Boston area. All subjects were right- handed and had normal or corrected-to-normal vision. Nine subjects (3 female) participated in Experiment 1, and 9 subjects ( 5 female) took part in Experiment 2. Four subjects participated in both experiments. Subjects in Experiment 1 ranged in age from 24 to 38 years, and subjects in Experiment 2 ranged in age from 25 to 38 years.

\section{Visual stimuli and experimental paradigm}

Experiment 1 (VWM change detection). Stimuli were created in MATLAB (The MathWorks) using the Psychophysics Toolbox extension (Brainard, 1997; Pelli, 1997) and were presented using a liquid crystal display projector illuminating a screen within the scanner bore. Subjects fixated on a centrally located cross while 12 oriented colored bars were presented (six in each hemifield). The number of bars presented in each hemifield remained constant across trials, but the number of memory targets presented on a given trial varied from 1 to 4 . The remaining bars in the display served as distractors (Fig. 1A). Targets and distractors were distinguished by color, with targets denoted by red and distractors denoted by blue. Each bar subtended $0.25^{\circ} \times 2.5^{\circ}$ of visual angle. Targets were limited to either the right or left hemifield (counterbalanced across blocks). Subjects were instructed to remember the orientation $\left(0^{\circ}, 45^{\circ}\right.$, $90^{\circ}, 135^{\circ}$ ) of the target items in the display. The memory sample display was presented for $200 \mathrm{~ms}$ followed by a $1000 \mathrm{~ms}$ delay period. After the sample and delay period, a memory probe was presented for $1800 \mathrm{~ms}$. A $1000 \mathrm{~ms}$ fixation period separated each trial. On half of the trials, one of the target bars changed its orientation from the sample period to probe period. On the other half of the trials, the memory probe array was identical to the sample array. Subjects could respond during either the memory probe or the intertrial fixation period by pressing a key to indicate that the orientation of a target had changed, or a separate key if it had not changed. The magnitude of the change was always $90^{\circ}$ (e.g., $0^{\circ}-90^{\circ}$ or $45^{\circ}-135^{\circ}$ ). During sensorimotor control trials, subjects were presented a display consisting entirely of distractors and were instructed to press either key during the probe or intertrial fixation period.

Experiment 2 (visual attention Multiple Object Tracking [MOT]). Stimuli were generated and presented using Python with the VisionEgg software package (Straw, 2008; Bettencourt et al., 2011). The display consisted of two spatially offset rectangular regions, one per hemifield, each containing six white disks and a small centrally located fixation cross (Fig. 1B). At the onset of each trial, four target disks were highlighted in red for $1500 \mathrm{~ms}$ before changing back to white for $500 \mathrm{~ms}$. To encourage subjects to maintain central fixation, two targets were restricted to the left visual hemifield and two were restricted to the right visual hemifield. As a result, holding central fixation is the optimal strategy for tracking all targets. Following the cue period, all disks in the display moved in random directions at a constant speed of $4.8^{\circ}$ s for $12 \mathrm{~s}$. A repulsion algorithm was used that aggregated the distance between each disk and the edges of each hemifield display to determine the direction of movement. The closer a disk came to these objects, the more strongly it was directed away. As a result, disks repulsed off other disks and the hemifield display edges, preventing any overlap. Subjects were instructed to maintain fixation on the central fixation cross and covertly attend to the cued target disks as they moved around the display. Once the disks stopped moving, a single disk was highlighted in blue for $3000 \mathrm{~ms}$. Subjects were asked to respond by pressing a key if the probed disk was one of the original targets, or to press a separate key if it was not a target. A $1000 \mathrm{~ms}$ blank fixation interval separated each trial. At the onset of sensorimotor control trials, every disk in the display was highlighted in red during the cue period. In this condition, subjects were instructed to refrain from tracking the disks and to press either key during the probe period. Subjects practiced the task before scanning. Behavioral data from all but one subject were lost before they could be analyzed. However, 19 additional subjects were previously scanned while performing the same paradigm with a slice prescription that did not include the cerebellum. These subjects in addition to the remaining subject $(n=20)$ performed the task with a mean accuracy of $63.06 \%$, indicating that, although the task was challenging, subjects were generally able to perform the task. There is little reason to believe that the two subsets of subjects should differ significantly in their performance. 
A

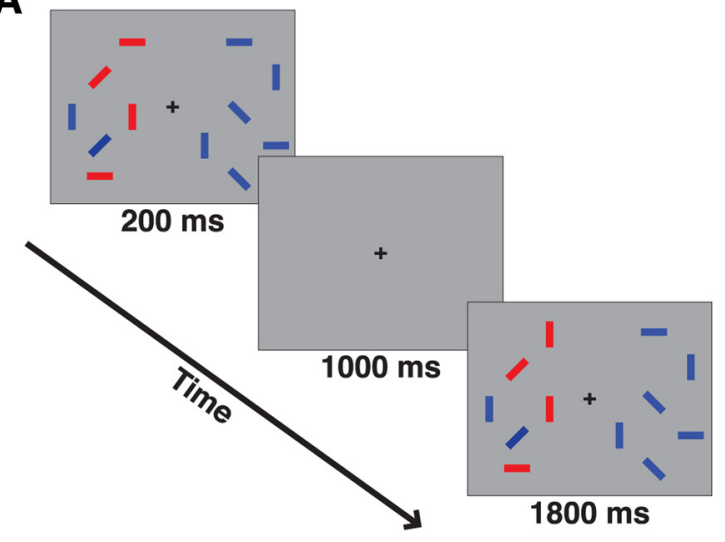

B

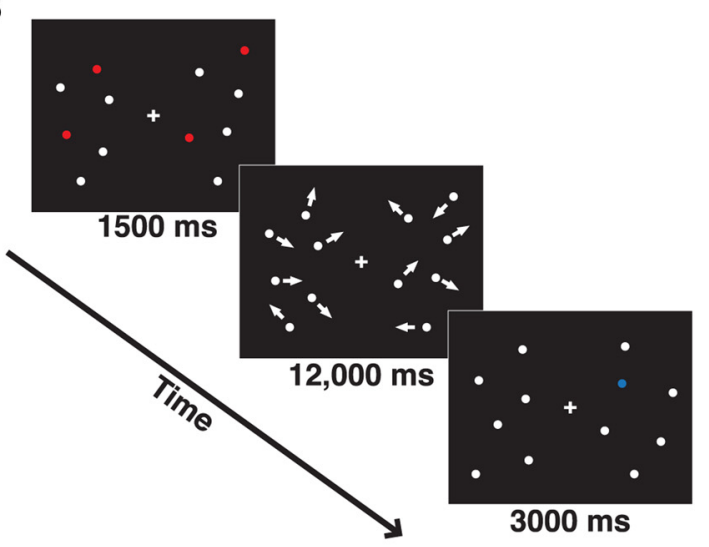

C
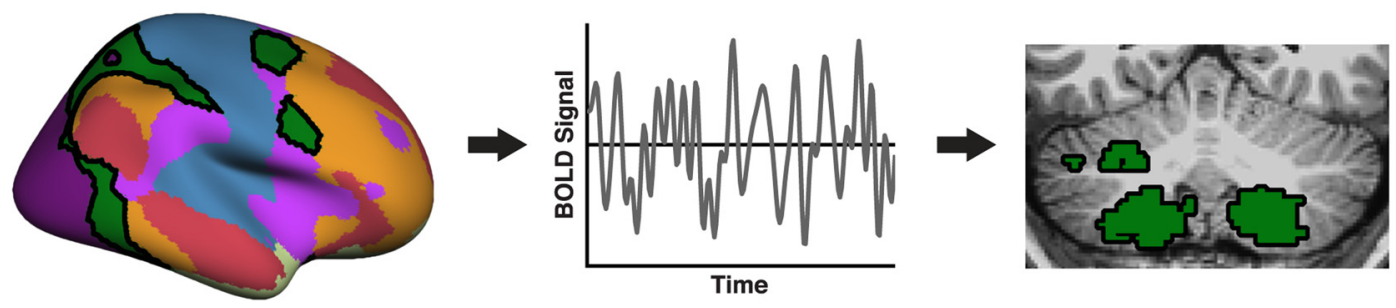

Figure 1. Experimental stimuli and methods. A, VWM change detection paradigm. Participants were asked to maintain central fixation and remember the orientation of target bars (red) and ignore distractor bars (blue). An array of oriented bars was presented (200 ms), then a blank screen (1000 ms), and finally a second array of bars (1800 ms) that was either identical or differed in the orientation of a single target bar (change on $50 \%$ of trials). Participants indicated with a key press whether or not a change occurred in the display. $\boldsymbol{B}$, Visual attention MOT paradigm. Participants were presented a cue display, which highlighted 4 of 12 total disks for 1.5 s. Participants were instructed to maintain central fixation while attentively tracking cued disks ( 2 in left visual field, 2 in right visual field) as they moved around the display. After $12 \mathrm{~s}$, the disks stopped moving and participants indicated whether a single highlighted disk was one of the original targets. C, Cerebellar Rols defined by intrinsic resting-state functional connectivity with cortical networks. Mean time courses were extracted from six cortical networks (Yeo et al., 2011) and correlated with every cerebellar voxel. ROls were created via a winner-take-all procedure that assigned each above-threshold voxel to the network with which it had the strongest correlation.

Magnetic resonance data acquisition. Data were acquired from a 3 Tesla Siemens TIM Trio magnetic resonance imager located at the Center for Brain Science at Harvard University in Cambridge, Massachusetts. A 32-channel head coil was used for all scans. T2*-weighted EPI (BOLD) images were acquired using a slice-accelerated EPI sequence that permits simultaneous multislice acquisitions using the blipped-CAIPI technique $\left[\mathrm{TR}=2 \mathrm{~s}, \mathrm{TE}=30 \mathrm{~ms}\right.$; flip angle $=80^{\circ} ; 6 / 8$ partial-fourier acquisition $]$ (Setsompop et al., 2012). A total of 69 slices were acquired with a slice acceleration factor of 3 and $0 \%$ skip, covering the whole brain, including the cerebellum. Images were acquired at a nominal $2 \mathrm{~mm}$ isotropic spatial resolution (matrix size $=108 \times 108 \times 69$ ).

In the VWM study (Experiment 1), each subject completed eight runs (total time per run $=6 \mathrm{~min} 16 \mathrm{~s}$ ). Each run comprised $1034 \mathrm{~s}$ task blocks and $16 \mathrm{~s}$ of blank fixation before the first block and after the last block. Each block consisted of a $2 \mathrm{~s}$ cue, which indicated the location of the target stimuli (left or right hemifield), followed by $84 \mathrm{~s}$ trials. In the MOT study (Experiment 2), subjects completed four runs (total time per run $=$ 4 min $56 \mathrm{~s}$ ), comprised of 16 alternating active and sensorimotor control blocks, each lasting $18 \mathrm{~s}$. The $4 \mathrm{~s}$ of blank fixation was presented before and after the task blocks. In both experiments, subjects underwent 2 or 3 resting-state scans using identical scan parameters (each 180 TRs; 6 min duration). During the resting-state scans, subjects were instructed to let their minds wander while maintaining fixation on a centrally located crosshair.

Data analysis. Functional and resting-state data were analyzed using the FreeSurfer FS-FAST software package (version 5.3.0) (Charlestown; http://surfer.nmr.mgh.harvard.edu/) (Fischl, 2012). The following preprocessing steps were performed: slice-time correction, motioncorrection, spatial smoothing ( $3 \mathrm{~mm}$ FWHM), and spatial normalization to the FreeSurfer "fsaverage" brain (MNI305) using a 6 parameter affine transformation. Single-subject data were analyzed voxelwise using a general linear model that included a predictor for each task condition (Experiment 1: set size 1 left, set size 1 right, set size 4 left, set size 4 right, sensorimotor control; Experiment 2: attend and sensorimotor control). To control for activation due to cue reorientation, cue time points were included as nuisance regressors in the model. Singular value decomposition reduced the 6 motion correction vectors to 3 eigenvectors, which were also included as nuisance regressors in the model. The task regressors were convolved with a canonical hemodynamic response function before fitting. This canonical hemodynamic response was modeled by a $\gamma$ function with a delay of $\delta=2.25 \mathrm{~s}$ and a decay time constant of $\tau=1.25$ (Boynton et al., 1996). $t$ tests were performed on each voxel to compare differences in activation between conditions. The significance of these activation differences was then overlaid onto the MNI305 template brain, as well as projected onto each hemisphere of the "fsaverage" cortical surface. Significant group-level task activation was corrected for multiple comparisons using cluster-based correction in FS-FAST. To generate a null hypothesis dataset, Monte Carlo simulations were performed to generate random volumes of normally distributed values that were smoothed with a FWHM estimated from the group analysis residuals. Significant clusters were identified by thresholding group statistical maps voxelwise $(p<0.05)$ followed by cluster thresholding at a corrected $\alpha$ of $p<0.05$.

Intrinsic functional connectivity analysis. We performed resting-state functional connectivity analysis from cortex to cerebellum, using groupaveraged cortical network seeds identified from a study of 1000 brains (Yeo et al., 2011) to identify cerebellar network ROIs uniquely within each subject. Additionally and independently, we performed a functional connectivity analysis from cerebellum to cortex, using task-evoked activation in the cerebellum to define a seed to identify the network of cortical areas intrinsically connected to task-sensitive cerebellar voxels. Resting-state data were further preprocessed in MATLAB. Head-motion regression (6 motion parameters and their 6 temporal derivatives), whole-brain signal regression, and ventricular and white matter signal regression were performed (Van Dijk et al., 2010). We then calculated framewise displacement by taking the sum of the absolute derivatives of 
the 6 motion parameters for each time point (Power et al., 2012). A threshold of $0.5 \mathrm{~mm}$ was set to identify time points with excessive motion. To avoid artifact spread during bandpass filtering, high motion time points were replaced using linear interpolation (Carp, 2013). Bandpass filtering was then performed to extract frequencies between 0.01 and $0.08 \mathrm{~Hz}$. After filtering, high-motion time points were removed.

Cortical seed connectivity analysis. For our cortical seeds, we defined 6 composite ROIs using a publicly available parcellation that was originally defined using a cluster-based intrinsic functional connectivity analysis of 1000 subjects (Yeo et al., 2011). Each of these composite seeds comprised all of the ROIs in one of 6 cerebral cortical networks: the DAN, ventral attention network (VAN), CCN, somatomotor network (SOM), limbic network (LIMB), and the DMN. A seventh network, the visual network, was excluded a priori due to the finding that it does not share significant connectivity with the cerebellum (Buckner et al., 2011). Additional analyses used an alternative definition of DAN from Power et al. (2011). To create a bilateral composite ROI, we projected MNI coordinates onto the Freesurfer "fsaverage" cortical surface. These coordinates were then iteratively dilated to a size of 61 vertices (diameter $\sim 8 \mathrm{~mm}$ ). A mean time course was calculated for each seed ROI. These mean time courses were then correlated against every voxel in the brain, including the cerebellum. The resulting correlation maps were then $z$-transformed using Fisher's $r$-to- $z$ transformation. To compute the voxelwise correlation between cerebellar task activation and connectivity, we computed the mean $z$ value for each cerebellar voxel across subjects.

Cerebellar ROI creation. To define cerebellar ROIs corresponding with each cortical network in individual subjects, a cerebellar mask was applied to individual subject functional connectivity $z$-maps (Fig. $1 C)$. The extracted data were thresholded at a $z$ of 0.2 . To ensure our results were robust to the chosen threshold, additional analyses were performed with ROIs defined with a lower threshold $(z>0.1)$ and a higher threshold $(z>0.3)$. A winner-take-all procedure was then performed so that each above-threshold voxel was assigned to the network with which that voxel had the strongest correlation. Each network ROI was then binarized to create a volumetric mask. To minimize the inclusion of false-positives in our ROIs, we created a dilated mask that effectively isolated clusters of correlated voxels of sufficient size. To create the dilated mask, network ROIs were iteratively smoothed with a boxcar kernel and thresholded (threshold = 6/27; 5 neighbors). Thus, voxels with $<5$ neighbors were excluded from the dilated mask. This process was repeated three times. The dilated mask was then applied to the unsmoothed ROIs. To be included in the analysis, an ROI had to exceed a threshold of $100 \mathrm{~mm}^{3}$. In Experiment 1, the SOM ROI of one subject did not meet this threshold.

To assess the effect of ROI on percentage signal change for each contrast, we used the SPSS mixed-model procedure to fit a marginal linear model. In contrast to a more traditional repeated-measures ANOVA model, a marginal linear model does not exclude cases with missing values and can flexibly model the dependency introduced by within-subject measures (West, Welch and Galecki, 2014). ROI was specified as a repeated measure, and subject ID was included as a grouping variable. Within-subject error was modeled using an unstructured covariance structure, which produced a unique variance estimate for each ROI and a unique covariance estimate for each pair of ROIs. A marginal linear model produces valid SE estimates and more efficient statistical tests of fixed parameters by more accurately modeling the error covariance structure (Littell et al., 1998). It should be noted that SPSS uses the Satterthwaite approximation to calculate degrees of freedom and, as a result, can produce noninteger values. The model was fitted using maximum likelihood estimation. Post hoc comparisons were corrected for multiple comparisons using the Holm-Bonferroni method.

Hemispheric ROI analysis. To examine differences in activation between hemispheres, we created hemisphere-specific ROIs in the cortex and cerebellum. Cortical ROIs were created by splitting the Yeo DAN representation into 4 ROIs (iPCS, sPCS, IPS, $\mathrm{MT}^{+}$) in each hemisphere. Hemisphere-specific cerebellar ROIs were created by applying hemispheric masks to the cerebellar ROI defined by connectivity with the cortical DAN. Mean percentage signal change was then extracted from each ROI. Hemispheric differences were assessed by performing paired $t$ tests for each ROI (corrected for multiple comparisons).

Cerebellar seed connectivity analysis. In each experiment, we performed an additional and statistically independent functional connectivity analysis. Our goal was to reveal, independent of any presumed cortical network structure, the cerebral cortical regions that exhibit intrinsic functional connectivity with the cerebellar regions strongly recruited during VWM and visual attention task performance. Seed regions within the cerebellum were defined in individual subjects by significant activation $(p<0.01)$ within lobules VIIb/VIIIa for the set size 4 sensorimotor control contrast (Experiment 1), the set size 4 set size 1 contrast (Experiment 1), and the active tracking-sensorimotor control contrast (Experiment 2). Our definition of lobules VIIb/VIIIa was obtained from the Spatially Unbiased Infratentorial Template (Diedrichsen, 2006; Diedrichsen et al., 2009). A time course was then averaged across cerebellar voxels included in our seed ROI. A Pearson's correlation coefficient was computed between our cerebellar seed time course and every vertex on the cortical surface. A random-effects group analysis was then performed, and significant group-level correlations were projected onto the inflated cortical surface of the FreeSurfer average (fsaverage) brain (Dale et al., 1999). We computed the overlap between connectivity and cortical task activation by calculating the Simpson overlap coefficient (Fuxman Bass et al., 2013). The Simpson coefficient is defined as the size of the intersection of two sets divided by the minimum size of the two sets. If one set is a perfect subset of the other set, the Simpson coefficient is equal to 1 .

Hierarchical cluster analysis. To investigate the network structure of activated regions in the cerebellum and cortex, we performed a hierarchical cluster analysis on seed-to-seed resting-state correlations. Seeds were defined in individual subjects by significant functional activation $(p<0.01)$ in the cortex and cerebellum. To ensure that functional connectivity seeds did not differ greatly in size, we used anatomical masks to constrain our functionally defined ROIs. Cortical masks were taken from a parcellation of the cortex freely available in the FreeSurfer package (Fischl et al., 2004; Destrieux et al., 2010). Cortical seed ROIs were defined for each hemisphere within IPS, sPCS, iPCS, $\mathrm{MT}^{+}$, dorsal anterior cingulate cortex (dACC), anterior insula (aInsula), and posterior callosal sulcus (CAS-p). To anatomically constrain our cerebellar seed ROI, we again used a mask encompassing cerebellar lobules VIIb and VIIIa obtained from the Spatially Unbiased Infratentorial Template (Diedrichsen, 2006; Diedrichsen et al., 2009). If we could not define a seed within a particular mask due to the lack of above-threshold functional activation, we used a seed defined from the group analysis map. To ensure that we could create group-defined seeds for all regions in which a seed could not be defined in individual subjects, we used a slightly lower threshold $(p<$ $0.05)$ to create seeds from the Experiment 2 group map. A seed-to-seed correlation matrix was then computed for each subject. To increase statistical power, we collapsed correlation matrices from both studies into a single group correlation matrix. Before averaging, correlation values for each subject were transformed using the Fisher $r$-to- $z$ transformation to address the issue of nonadditivity of correlation coefficients. As 4 subjects participated in both studies, we first computed a mean correlation matrix for each overlapping subject. Because of the discrepancy in the number of resting-state runs between Experiments 1 and 2, same-subject correlation matrices were weighted by the number of resting-state TRs in each session. Treating each row of the group correlation matrix as a vector in a 16 dimensional space, we computed pairwise Euclidean distance between each region's pattern of connectivity. We then applied Ward's linkage algorithm to these distances, which forms each new cluster by merging the two clusters that lead to the minimum possible increase in the total sum of squares of the node to centroid distances. Cluster tree branch points were validated using a bootstrapping approach (Dosenbach et al., 2007). A total of 1000 bootstraps were created by randomly sampling with replacement from our pool of 14 individual subject seedto-seed correlation matrices. Generated bootstrap correlation matrices were averaged to form a mean correlation matrix. Each mean bootstrap matrix was clustered to create 1000 bootstrap cluster trees. Bootstrap confidence values for each branch point were computed by counting the 
number of iterations in which a subtree consisted of the same ROIs as the original tree.

Eye movement monitoring. Subjects were instructed to maintain fixation on a centrally located cross throughout all scans. In Experiment 1, eye position was monitored using an EyeLink 1000 from SR research. Eye movement data were analyzed using custom scripts written in MATLAB. To assess whether differential cerebellar activation can be attributed to eye movements, distance from fixation for each trial was calculated by taking the root mean square (RMS) difference of the horizontal and vertical traces from the median value for the trial. These values were then averaged across trials of each condition to produce an average value for each subject. Because of technical difficulties, eye movement data could not be obtained for one subject.

\section{Results}

\section{VWM results}

Behavior. Subjects performed well in the VWM change detection task during fMRI scanning. In the set size 4 (SS4) condition, mean accuracy was $79.64 \%$ and subjects effectively held $2.52 \mathrm{ob}-$ jects in VWM (Pashler, 1988). In the set size 1 (SS1) condition, accuracy was $97.57 \%$ and subjects effectively held 0.97 objects in VWM. Subjects held more items in VWM during SS4 versus SS1 $\left(t_{(8)}=12.74, p<0.001\right)$.

\section{Eye-tracking}

Because the cerebellum is functionally linked to the motor system, it is critical to demonstrate that eye movements did not differ across conditions. We computed the RMS of eye position relative to fixation for each trial. There was no significant difference in mean RMS between conditions $\left(F_{(2,8)}=\right.$ 2.34, $p=0.158)$. Pairwise comparisons further revealed no significant difference in RMS between SS4 and both SS1 and the sensorimotor control (SS4 vs SS1: $t_{(8)}=-0.40, p=0.698$, uncorrected; SS4 vs control: $t_{(8)}=-2.09, p=0.070$, uncorrected). The trend in the SS4-Control comparison reflects greater RMS in the sensorimotor control condition. These measurements demonstrate that any activation observed in the contrast of high-load VWM to low-load VWM and the sensorimotor control condition cannot be attributed to greater eye movements during the high-load condition.

\section{Task-based fMRI and ROI analysis}

A random-effects group analysis of the fMRI data contrasting SS4 with the sensorimotor control condition revealed significant clusters of activation located within lobules VIIb/VIIIa bilaterally $($ MNI coordinates $=[-11.5,-85,-35.5] ;[7.5,-91,-30.5])$, consistent with the location of the functional connectivity DAN representation identified by Buckner et al. (2011). Significant clusters were also identified within lobule VI/Crus I bilaterally $(\mathrm{MNI}=[-43.5,-81,-22.5],[43.5,-80,-19.5])$. To better characterize these results, cerebellar ROIs were defined in individual subjects by intrinsic functional connectivity with six cortical networks from the Yeo 7-network parcellation (DAN, VAN, CCN, SOM, LIMB, and DMN; see Materials and Methods) (Yeo et al., 2011). Visualization of individual subject cerebellar fMRI activation and resting-state connectivity patterns revealed a similar pattern of cerebellar regions activated by VWM and intrinsically coupled with cortical DAN regions (Fig. $2 A-C$ ). The ROI analysis revealed that VWM task activation specifically targeted the cerebellar regions coupled with the cortical DAN (Fig. 2D). Mean percentage signal change differences between the SS4 condition and the sensorimotor control condition were extracted from each cerebellar network ROI. These values were entered into a marginal linear model. There was a significant effect of
ROI $\left(F_{(5,9)}=11.52, p=0.001\right)$. Post hoc comparisons (HolmBonferroni corrected) revealed that the cerebellar DAN ROI exhibited significantly greater activation than every other cerebellar network ROI (DAN vs VAN: $t_{(9)}=4.50, p=0.006$; DAN vs CCN: $t_{(9.01)}=5.40, p=0.002$; DAN vs SOM: $t_{(9.03)}=3.61, p=0.011$; DAN vs LIMB: $t_{(9.01)}=3.35, p=0.011$; DAN vs DMN: $t_{(9)}=$ $4.48, p=0.006)$. Only the cerebellar ROIs defined by connectivity with the cortical DAN and DMN significantly differed from 0 . The cerebellar ROI that coupled with the DAN exhibited a significant increase in signal $\left(t_{(9.14)}=3.26, p=0.048\right.$ corrected; uncorrected $p<0.01$ ), and the cerebellar ROI that coupled with the DMN exhibited a significant decrease in signal $\left(t_{(9)}=-3.92, p=\right.$ 0.021 corrected; uncorrected $p<0.01)$. These results were robust to the threshold chosen to define cerebellar ROIs. All comparisons remained significant for ROIs defined with a lower threshold $(z>0.1)$ or a higher threshold $(z>0.3)$.

\section{Load-dependent responses}

A load-dependent response profile (i.e., increasing activation with increasing numbers of items held in VWM) is a defining characteristic of cortical regions implicated in VWM. To assess whether the cerebellar subregions exhibit load dependence, we contrasted SS4 with SS1 within each of our cerebellar ROIs. There was a significant effect of cerebellar ROI $\left(F_{(5,8.78)}=39.84, p=\right.$ $0.000009)$. Again, this effect was driven by significantly greater percentage signal change within the cerebellar ROI coupled to DAN in relation to every other cerebellar ROI (DAN vs VAN: $t_{(9)}=4.47, p=0.003 ; \mathrm{DAN}$ vs CCN; $t_{(9)}=4.08, p=0.003 ; \mathrm{DAN}$ vs SOM: $t_{(9)}=5.74, p=0.0009$; DAN vs LIMB: $t_{(9)}=9.55, p=$ 0.00003; DAN vs DMN: $t_{(9)}=7.94, p=0.0001$; Holm-Bonferroni corrected) (Fig. $2 E$ ). We again found that only the cerebellar ROIs defined by connectivity with the cortical DAN and with the cortical DMN exhibited a significant difference in percentage signal change (DAN: $t_{(9)}=5.69, p=0.002$, corrected; DMN: $t_{(9)}=$ $-4.52, p=0.007$, corrected). There was also a significant activation difference within the ROIs defined by connectivity with the VAN and CCN, but this effect was reduced to a trend after correction for multiple comparisons (VAN: $t_{(9)}=3.10, p=0.051$ corrected; $\mathrm{CCN}: t_{(9)}=2.91, p=0.052$ corrected).

\section{Resting-state functional connectivity versus task activation}

To further quantify the relationship between cerebellar taskevoked activation and intrinsic functional connectivity to cortical networks, we examined, for all cerebellar voxels (independent of the above ROI definitions), the voxelwise correlation between VWM activation and connectivity to the DAN and DMN. We computed the mean normalized activation (SS4 vs control and SS4 vs SS1) and mean normalized correlation to the cortical DAN and DMN of each cerebellar voxel across subjects and then correlated these two measures. There was a strong positive correlation between VWM-evoked activation and DAN connectivity (SS4 vs control: $r=0.60$; SS4 vs SS1: $r=0.62$ ), and a robust negative correlation between VWM activation and DMN connectivity (SS4 vs control: $r=-0.73$; SS4 vs SS1: $r=-0.65$ ) (Fig. 3 ). These strong correlations indicate that intrinsic functional connectivity patterns with the DAN and DMN are robust predictors of VWM task activation across individual cerebellar voxels.

\section{Hemispheric bias}

A right hemisphere bias is commonly observed in studies of spatial VWM, such that right hemisphere VWM regions exhibit greater activation than left hemisphere VWM regions (e.g., Belger et al., 1998; Rypma and D'Esposito, 1999). The cortex is an- 
A

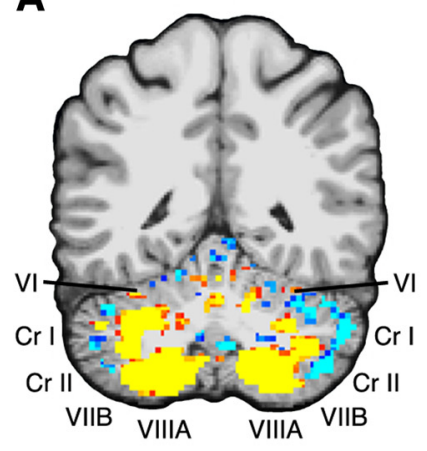

B

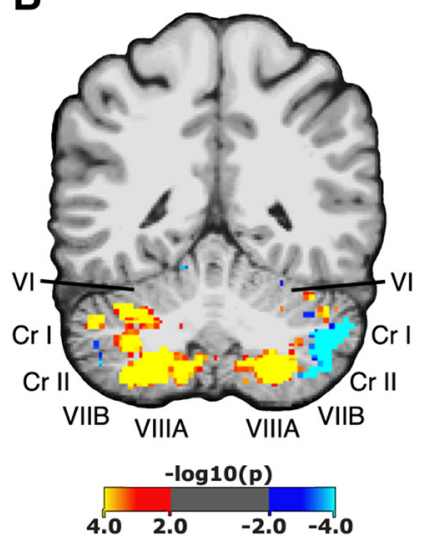

C

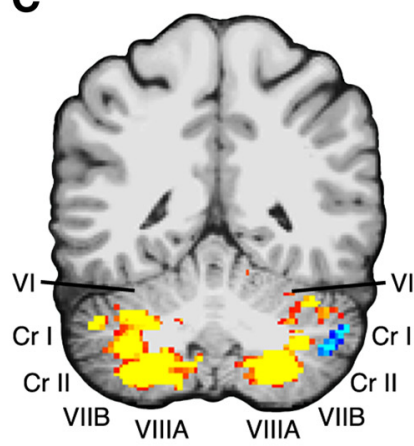

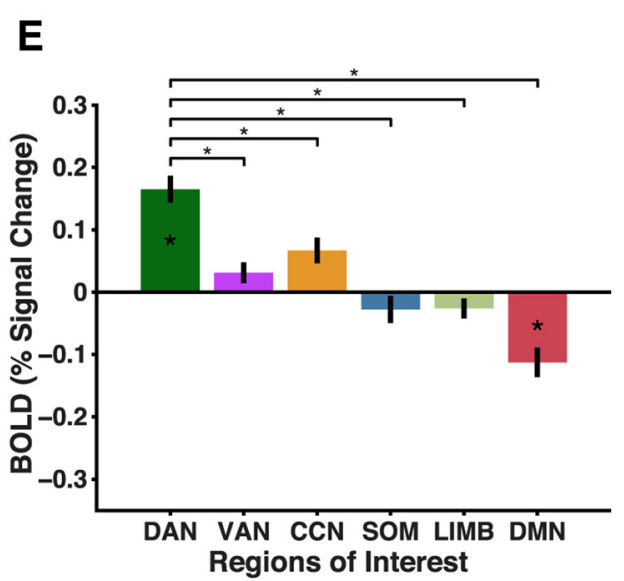

Figure 2. Experiment 1: VWM and functional connectivity results. $\boldsymbol{A}$, Cerebellar voxels that exhibit significant positive correlation with cortical DAN (hot colors) in one subject. $\boldsymbol{B}$, VWM task activation in cerebellum for the same subject, contrasting the set size 4 (SS4) condition (hot colors) versus sensorimotor control (cool colors). C, Cerebellar VWM activation contrasting the SS4 condition (hot colors) versus the set size 1 (SS1) condition (cool colors). D, E, Group analysis of task activation in cerebellum. Cerebellar ROls for individual subjects were defined by intrinsic functional connectivity with cortical networks. D, Bars represent mean percentage signal change $(n=9)$ for the SS4 condition relative to the sensorimotor control. Error bars indicate within-subject SEM. $\boldsymbol{E}$, Mean percentage signal change $(n=9)$ for the SS4 condition relative to the SS1 condition. Error bars indicate within-subject SEM. ${ }^{*}$ denotes significance $(p<0.05$ corrected).

atomically connected with the contralateral hemisphere of the cerebellum via the pons. Therefore, if a cerebellar region participates in VWM processing, we would expect to observe a left hemisphere bias in the cerebellum. We split the cortical DAN representation from Yeo et al. (2011) 7 network parcellation into 4 ROIs in each hemisphere (iPCS, sPCS, IPS, $\mathrm{MT}^{+}$). Within all cortical ROIs, the right hemisphere exhibited stronger activation than the left hemisphere (LH vs RH for SS4 minus control: iPCS: $t_{(9)}=3.28, p=0.029$; $\operatorname{sPCS}: t_{(9)}=2.94, p=0.033$; IPS: $t_{(9)}=$ 5.33, $p=0.002 \mathrm{MT}^{+}: t_{(9)}=2.34, p=0.044$; LH vs RH for SS4 minus SS1: iPCS: $t_{(9)}=3.22, p=0.021$; $s$ PCS: $t_{(9)}=4.90, p=$ 0.003 ; IPS: $t_{(9)}=5.17, p=0.003 ; \mathrm{MT}^{+}: t_{(9)}=2.23, p=0.053$; Holm-Bonferroni corrected) (Fig. 4A). To create cerebellar ROIs, we applied hemispheric masks to the cerebellar ROI defined by intrinsic functional connectivity to the DAN in individual subjects to create an ROI for each hemisphere. We found evidence for hemispheric bias in the cerebellum mirroring the bias observed in the cortex. Within cerebellar regions defined by functional connectivity with the cortical DAN, the left hemisphere exhibited significantly greater activation than the right hemisphere (SS4 minus control: $t_{(9)}=5.54, p=0.002$, corrected; SS4 minus SS1: $t_{(9)}=4.21, p=0.007$, corrected) (Fig. $4 B$ ).

\section{Cerebellum-to-cortex intrinsic functional connectivity}

As a further analysis of the interactions between cortex and cerebellum in VWM, we reversed direction and performed a cerebellar-to-cortex intrinsic functional connectivity analysis. The seed regions for this seed-to-vertex intrinsic functional connectivity analysis were defined in the cerebellum by significant cerebellar VWM activation (SS4 vs control and SS4 vs SS1 contrasts) within lobules VIIb/VIIIa $(p<0.01)$ in individual subjects. Critically, this seed definition depends only on task activation and is completely independent of the definitions used in the cerebellar ROI analyses of Figure 2. We then compared this cortical pattern of intrinsic functional connectivity with each cortical network definition from the Yeo et al. (2011) parcellation, as well as to cortical VWM task activation. A random-effects group analysis of resting-state correlations revealed substantial bilateral overlap between the cortical regions identified by functional connectivity with task-activated cerebellum and the cortical regions directly activated by the VWM task bilaterally (SS4 vs control: overlap coefficient $=0.59$ left hemisphere, 0.62 right hemisphere; SS4 vs SS1: overlap coefficient $=0.59$ left hemisphere, 0.67 right hemisphere) (Fig. 5; black outlines indicate task activation). There was also remarkable overlap between cerebellum-to-cortex functional connectivity and the cortical DAN Yeo representation (SS4 vs control: overlap coefficient $=0.61$ left, 0.67 right; SS4 vs SS1: overlap coefficient $=0.60 \mathrm{left}, 0.69$ right) and to a lesser degree the CCN Yeo representation (SS4 vs control: overlap coefficient $=0.18$ left, 0.12 right; SS4 vs SS1: overlap coefficient $=$ 0.20 left, 0.16 right) and VAN Yeo representation (SS4 vs control: overlap coefficient $=0.19$ left, 0.22 right; SS4 vs SS1: overlap 
A
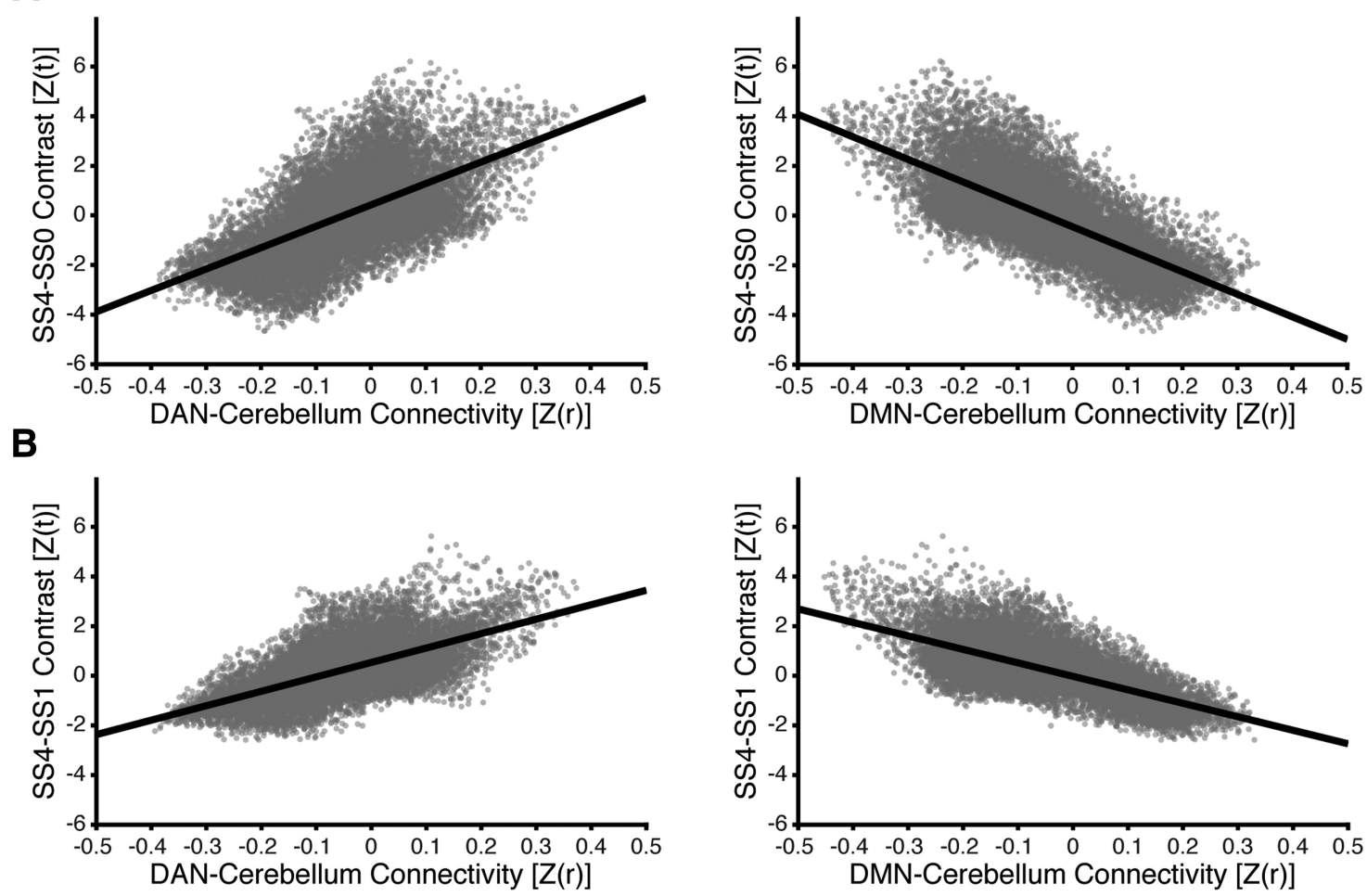

Figure 3. A, Relationship between mean normalized task activation ( $S S 4$ vs sensorimotor control) and mean normalized correlation with the cortical DAN (left) and the cortical default network (right) for every voxel in the cerebellum. B, Relationship between voxelwise mean normalized activation (SS4 vs SS1 contrast) and mean normalized correlation with the cortical DAN (left) and the cortical default network (right).
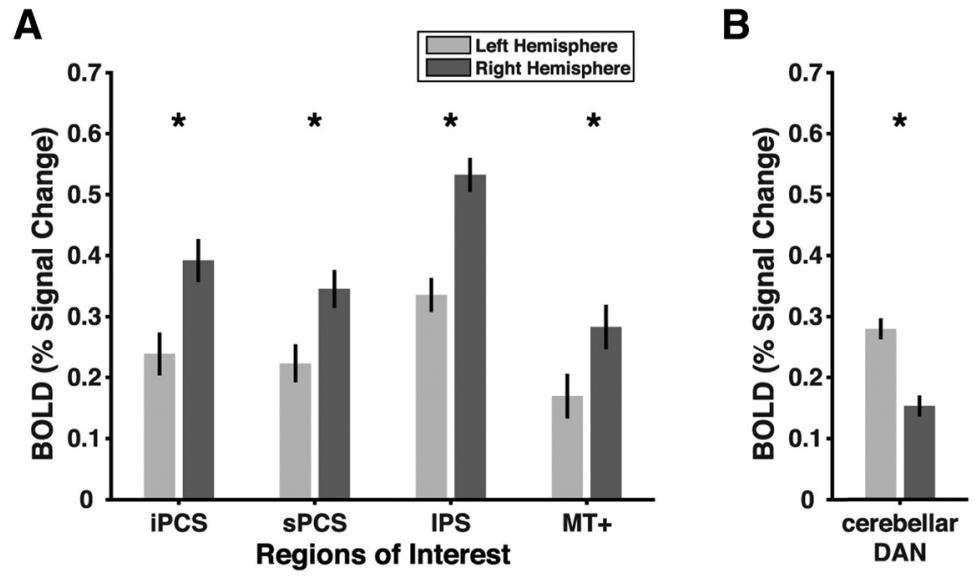

Figure 4. Hemispheric asymmetry in VWM activation reflects contralateral corticocerebellar structural connectivity. $A$, Cortical regions of the DAN exhibit a right hemisphere activation bias. $\boldsymbol{B}$, A left hemisphere activation bias occurs in the cerebellar ROls defined by functional connectivity with the cortical DAN. Bars represent average percentage signal change for SS4 condition compared with sensorimotor control for each hemisphere. Error bars indicate within-subject SEM. * denotes significance ( $p<$ 0.05 corrected).

coefficient $=0.21$ left, 0.23 right). Overlap with all other network representations did not exceed 0.05 . To extend these results, we also computed the overlap between cerebellum-to-cortex functional connectivity and an alternative definition of DAN from the Power et al. (2011) network parcellation. There was an even greater degree of overlap between connectivity and the Power DAN ROIs (SS4 vs control: overlap coefficient $=0.80$ left, 0.77 right; SS4 vs SS1: overlap coefficient $=0.77$ left, 0.70 right). Therefore, VWM-activated cerebellar regions exhibit a pattern of intrinsic functional connectivity that aligns with multiple defini- tions of the DAN and robustly predicts the pattern of cortical VWM activation.

\section{Experiment 2: MOT}

To demonstrate the generality of the cerebellar task activation results, we performed a second experiment, using a different attentionally demanding paradigm. In Experiment 2, subjects performed a sustained attention MOT task, which required subjects to track cued discs in the presence of identical distractors. The attentional MOT paradigm yielded a similar neural pattern of results to the VWM change detection paradigm of Experiment 1. A randomeffects group analysis again identified significant clusters of activation within lobules VIIb/VIIIa bilaterally (MNI: [ $-6.5,-91.0$, $-28.5]$; $[32.5,-64.0,-43.5])$ and lobule VI/Crus I bilaterally (MNI: $[-33.5,-76.0$, $-21.5]$; [46.5, $-68.0,-23.5])$. Individual subject analyses revealed overlap of cerebellar visual attention task activation (Fig. 6B) and cortical DAN seed functional connectivity (Fig. 6A). An ROI analysis was performed to provide a quantitative measure of this within-subject cerebellar spatial correspondence across subjects. ROIs were defined by functional connectivity with the same six cortical networks as described in Experiment 1. Mean BOLD percentage signal change for the attend condition versus the sensorimotor control condition was obtained for each of the six cerebellar network ROIs and entered into a marginal linear model. There was a significant effect of ROI $\left(F_{(5,9)}=69.21, p=0.000001\right)$. Post hoc compari- 



Figure 5. Intrinsic functional connectivity of task-responsive cerebellar regions predicts cortical task activation. For this functional connectivity analysis, cerebellar lobule VIIb/VIIlla ROls were defined by VWM activation (SS4 vs sensorimotor control and SS4 vs SS1 contrasts). $A$, Color map displays cortical regions that exhibit significant ( $p<0.01$, group-level) intrinsic functional connectivity with cerebellar regions activated by $S S 4$ versus sensorimotor control contrast. Black outlines indicate cortical VWM task activation (cluster-corrected, SS4 vs sensorimotor control). $\boldsymbol{B}$, Cortical regions that exhibit significant ( $p<0.01$, group-level) intrinsic functional connectivity with cerebellar regions activated by SS4 versus SS1 contrast. Black outlines indicate significant SS4 versus SS1 activation (cluster-corrected).

sons (Holm-Bonferroni corrected) demonstrated that the cerebellar ROI defined by intrinsic functional connectivity with the DAN exhibited significantly greater activation relative to every other cerebellar network ROI (DAN vs VAN: $t_{(9)}=3.35, p=0.012$; DAN vs CCN: $t_{(9)}=5, p=0.002 ;$ DAN vs SOM: $t_{(9)}=3.58, p=0.012 ;$ DAN vs
LIMB: $t_{(9)}=5.27, p=0.002$; DAN vs DMN: $t_{(9)}=10.02, p=$ 0.00002) (Fig. 6C). Of the six cerebellar network ROIs, only those defined by intrinsic functional connectivity with the DAN or the DMN significantly differed from zero. The DAN-coupled ROI showed a significant increase in signal (DAN: $t_{(9)}=4.24, p=0.013$ 
A

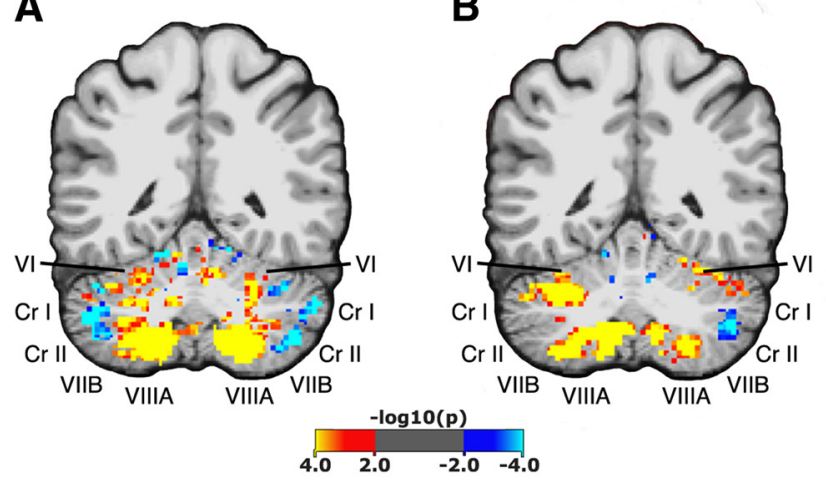

C

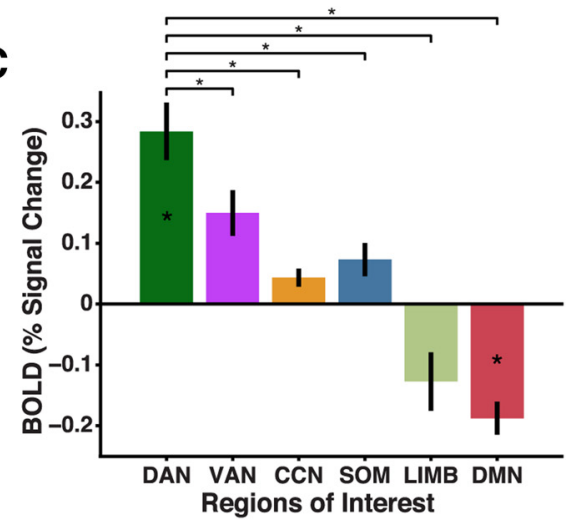

D
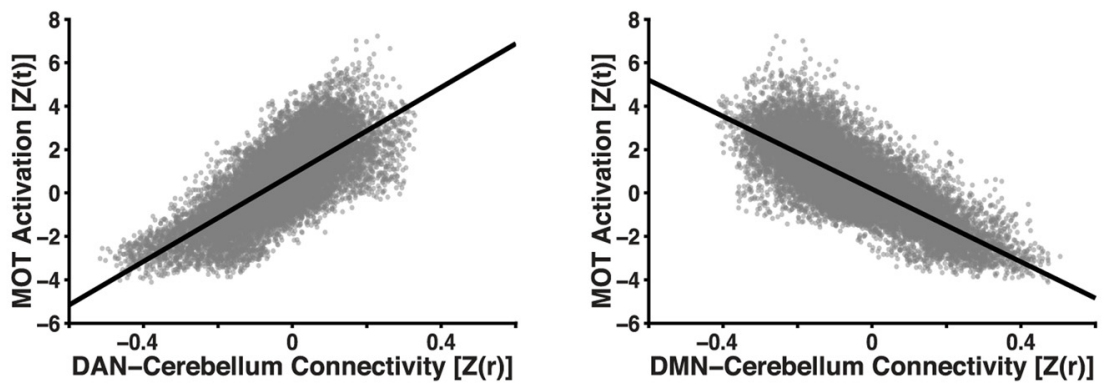

Figure 6. Experiment 2: MOT sustained attention and functional connectivity results. $A$, Cerebellar voxels that exhibit significant positive correlation with cortical DAN (hot colors) in one subject. $B$, MOT task activation in cerebellum for the same subject, contrasting the "attend" condition (hot colors) versus sensorimotor control (cool colors). C, Group analysis of task activation in cerebellum. Cerebellar ROls for individual subjects were defined by intrinsic functional connectivity with cortical networks. Bar graph represents mean percentage signal change for the attend condition versus the sensorimotor control condition. Error bars indicate within-subject SEM. D, Relationship between mean normalized task activation (attend vs sensorimotor control) and mean normalized correlation with the cortical DAN (left) and the cortical default network (right) for every voxel in the cerebellum. ${ }^{*}$ denotes significance ( $p<0.05$ corrected).

corrected), whereas the DMN-coupled ROI showed a significant decrease in signal (DMN: $t_{(9)}=-4.16, p=0.013$ corrected).

\section{Resting-state functional connectivity versus task activation} To further explore the correspondence between attentional activation in the cerebellum and connectivity to cortical networks, we computed the voxelwise correlation between cerebellar MOT activation and either DAN or DMN connectivity. The correlation between task-evoked attentional activation and DAN connectivity was strongly positive $(r=0.74)$, whereas the correlation between task activation and DMN connectivity was strongly negative $(r=-0.77)$ (Fig. 6D). Cerebellar voxelwise connectivity with an alternative seed definition of cortical DAN (Power et al., 2011) yielded a similarly robust correlation with voxelwise MOT activation $(r=0.74)$. These results closely mirror the results of this analysis for the VWM task.

\section{Cerebellum-to-cortex intrinsic functional connectivity}

To examine whether the cerebellar and cortical regions coactivated during visual attention are also intrinsically coupled during rest, we performed a resting-state functional connectivity analysis using cerebellar seed regions defined by significant MOT activation $(p<0.01)$ and constrained by an anatomical lobule VIIb/VIIIa mask. We observed robust overlap between connectivity and cortical task-evoked activation (overlap coefficient $=$ 0.51 left hemisphere, 0.64 right hemisphere; see Fig. 7; black outlines indicate task activation). Additionally, we again observed substantial overlap between connectivity and the cortical Yeo DAN (overlap coefficient $=0.59$ left hemisphere, 0.57 right hemisphere). To a lesser extent, we also found overlap with the cortical Yeo VAN (overlap coefficient $=0.34$ left, 0.50 right) and cortical Yeo CCN (overlap coefficient $=0.14$ left, 0.14 right). The remaining networks (SOM, LIMB, and DMN) exhibited negligible overlap $(<0.05)$ with cerebellum-to-cortex functional connectivity. Additionally, we found a similar degree of overlap between cerebellum-to-cortex functional connectivity and the Power et al. (2011) definition of DAN (overlap coefficient $=0.69$ left, 0.66 right). Similar to the results for VWM, we found that intrinsic resting-state functional connectivity between MOTactivated cerebellar regions and the cortex preferentially aligns with the DAN and that the pattern of connectivity robustly predicts the pattern of MOT activation in cortex.

\section{Hierarchical cluster analysis}

Cortical activation in response to both tasks extended beyond the DAN to include a subset of the CCN, including dACC, aInsula, and CAS-p. To investigate whether activated portions of cerebellar lobules VIIb/VIIIa form an intrinsic node of the DAN, we performed agglomerative hierarchical clustering on seed-to-seed resting-state correlations of task-responsive regions in cortex and cerebellum. Hierarchical clustering of the distance (Euclidean) between functional connectivity patterns of task-activated regions revealed two distinct networks (Fig. 8). Cerebellar lobule $\mathrm{VIIb} / \mathrm{VIII} a$ and cortical DAN regions (iPCS, sPCS, IPS, $\mathrm{MT}^{+}$) formed one network, and cognitive control regions (dACC, aInsula, CAS-p) formed another network. A cophenetic correlation of 0.82 indicated that the cluster tree accurately reflected the original dissimilarity matrix. A 1000 iteration bootstrap procedure validated these findings. The cerebellar lobule VIIb/VIIIa ROI clustered with cortical dorsal attention regions on $89.0 \%$ of bootstraps. Additionally, on $60.9 \%$ of bootstraps, cerebellar regions were closer in distance to frontal and parietal DAN regions (iPCS, 

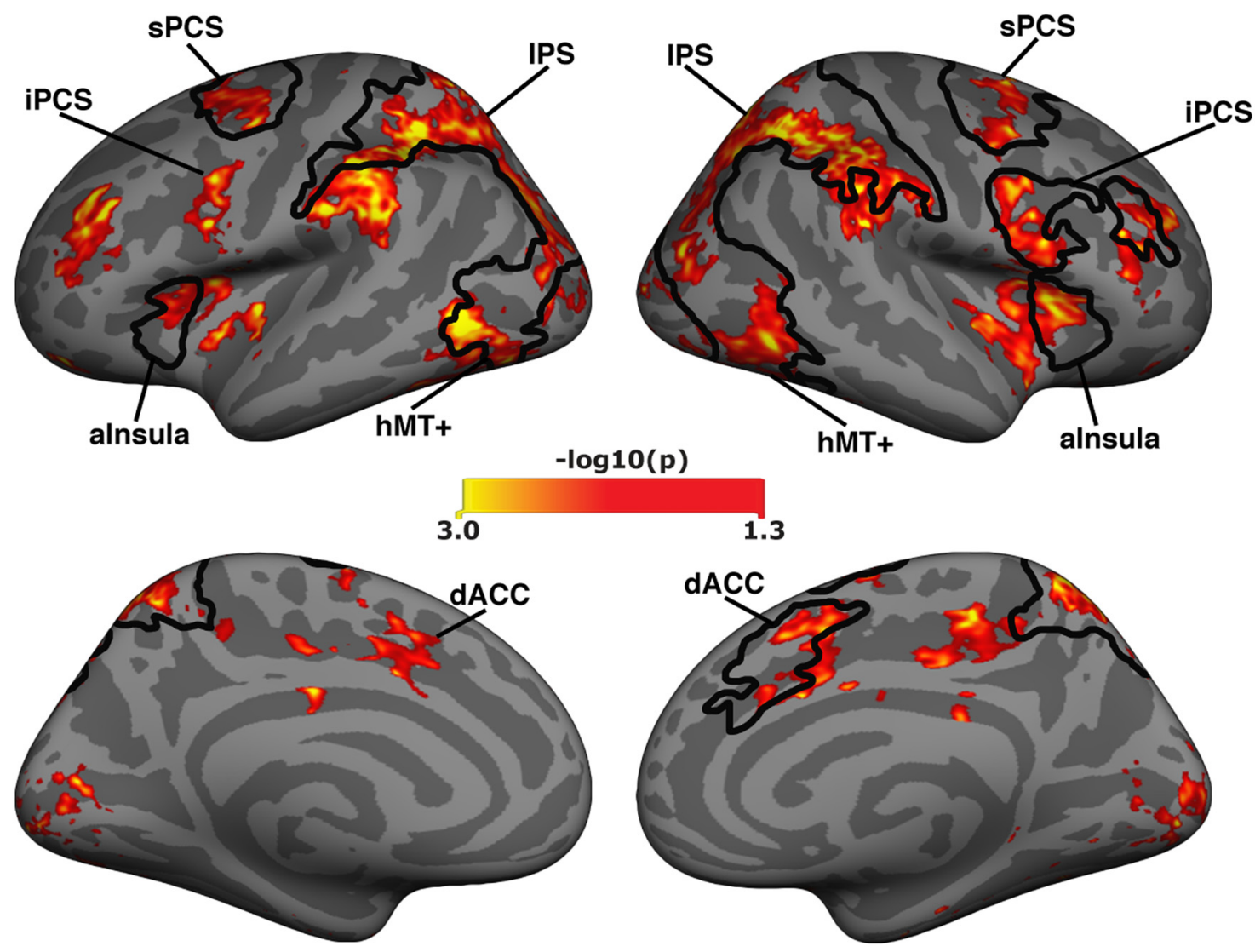

Figure 7. Intrinsic functional connectivity of MOT-responsive cerebellar regions aligns with cortical task activation. Cerebellar lobule VIIb/VIlla ROIs defined by significant MOT activation ( $p<$ 0.01 ; tracking vs sensorimotor control). Color map displays cortical regions that exhibit significant ( $p<0.01$, group-level) intrinsic functional connectivity with cerebellar regions activated by MOT. Black outlines indicate significant group-level cluster-corrected MOT task activation.

sPCS, and IPS) than $\mathrm{MT}^{+}$. These findings confirm that cerebellar regions recruited by working memory and attention occupy a privileged position within the hierarchy of the DAN.

\section{Discussion}

Cognitive processes, such as working memory and attention, are typically considered to fall under the purview of the cerebral cortex. In the present study, we challenge this notion and suggest that regions of the cerebellum make a general contribution to working memory and attentional processes as a core component of an attentional network spanning both cortical and subcortical structures. Using resting-state functional connectivity and task-based fMRI, we showed that cerebellar regions intrinsically coupled with the cortical DAN were robustly recruited by both a VWM paradigm and an attentional paradigm. The observed activation aligns with previous findings of DAN functional connectivity within cerebellar lobules VIIb/VIIIa (Buckner et al., 2011). Critically, activation in cerebellar lobules VIIb/ VIIIa was significantly higher during high-load VWM than during low-load

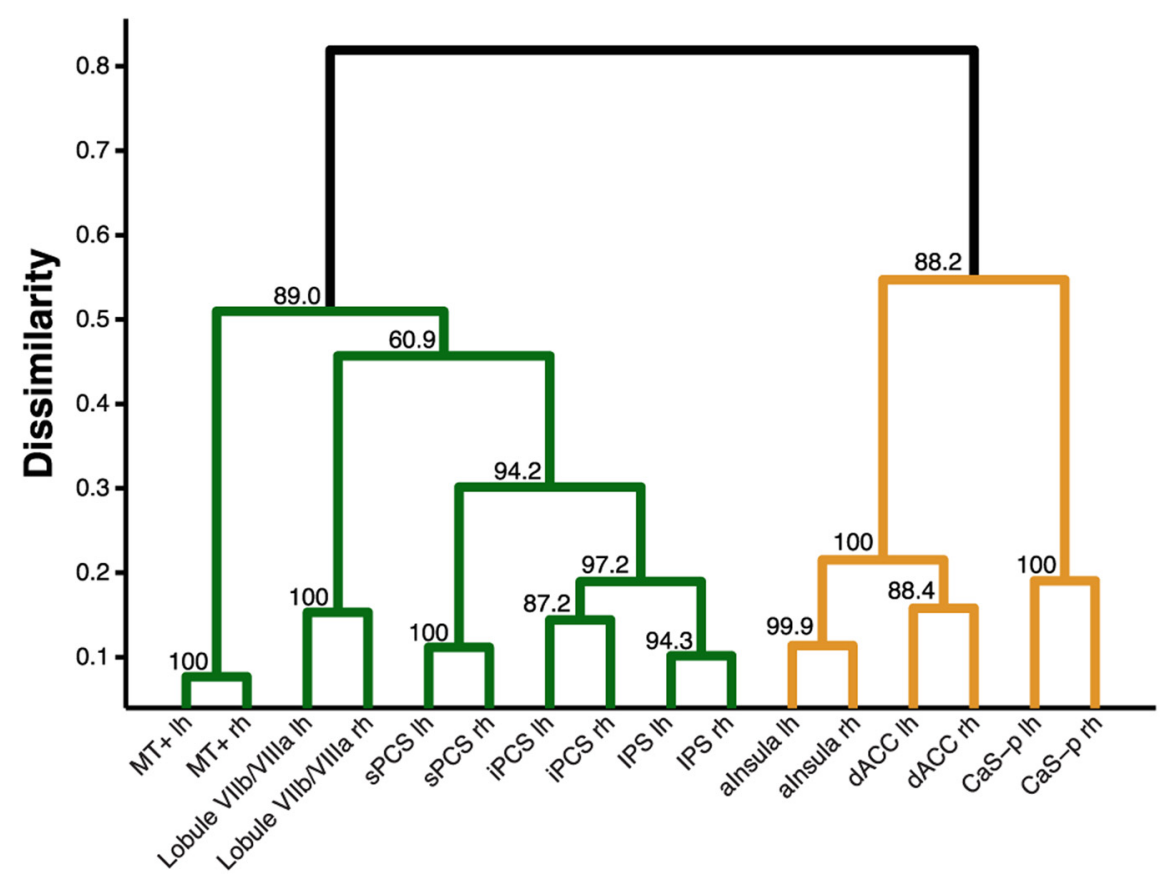

Figure 8. Cerebellar lobule VIIb/VIIla ROI groups into cortical DAN. Hierarchical cluster tree based on the Euclidean distance between seed-to-seed resting-state functional connectivity patterns of task-responsive regions in cortex and cerebellum. Values next to each branch point indicate confidence values based on the percentage of bootstraps in which a subtree consisted of the same ROIs (see Materials and Methods). Green represents cortical DAN. Orange represents cortical CCN. 
VWM. The observed load-dependent activation exhibited a high degree of specificity. Of the six cerebellar network representations, only the cerebellar regions exhibiting functional connectivity with the cortical DAN were significantly active across all contrasts. Additionally, we observed that cerebellar regions coupled with the cortical DMN were suppressed during task performance. To our knowledge, this is the first study to show that the antagonistic relationship between the DAN and DMN extends to the cerebellum, providing further evidence for the active participation of cerebellar nodes in whole-brain network function. Finally, we found that the intrinsic functional connectivity of taskactivated cerebellar regions was a robust predictor of cortical task activation, indicating that coactivated regions in the cortex and cerebellum also exhibit correlated spontaneous fluctuations during rest. Together, our results demonstrate that cerebellar lobules VIIb/ VIIIa play an active functional role in the intrinsic network dynamics of the DAN. We propose the DAN should be functionally reconceptualized as a corticocerebellar network that includes cerebellar lobules VIIb/VIIIa.

\section{Evidence for cerebellar contributions to visual attention and working memory}

There is accumulating evidence for cerebellar contributions to nonmotor function. Cerebellar activation has been reported during visual attention and/or working memory task performance (Allen et al., 1997; Desmond et al., 1997; Le et al., 1998; Chen and Desmond, 2005a, b; Kirschen et al., 2005; Tomasi et al., 2007; O'Reilly et al., 2008; Hautzel et al., 2009; Salmi et al., 2010; Stoodley et al., 2010, 2012; Kellermann et al., 2012; Striemer et al., 2015a). Anatomical tracers have been used to identify projections from the prefrontal cortex to the pons (Schmahmann and Pandya, 1997). Kelly and Strick (2003) further demonstrated the existence of polysynaptic connections between prefrontal cortex and cerebellum, thereby establishing that cognitive regions of the cortex are anatomically connected with the cerebellum. Additionally, closed-loop corticocerebellar prefrontal circuits are distinct from corticocerebellar motor circuits (Kelly and Strick, 2003) and are substantially larger in humans than in other primates (Ramnani, 2006). These greatly expanded closed-loop circuits between the cerebellum and multimodal association cortex provide an anatomical basis for cerebellar contributions to human cognition and participation in greater network function.

Clinical work has further substantiated the notion of cerebellar involvement in cognitive processing. Cerebellar lesions, even in the absence of cortical damage, have been shown to produce a variety of cognitive deficits (Schmahmann and Sherman, 1998; Schmahmann, 2004), including impairment of visual attention processes (Schweizer et al., 2007; Baier et al., 2010; Striemer et al., 2015a). The cerebellum has also been linked to attention deficit hyperactivity disorder. Attention deficit hyperactivity disorder is associated with reduced cerebellar volume (Castellanos et al., 2002; Mackie et al., 2007; Stoodley, 2014), decreased cerebellar activation during the performance of cognitive tasks (Valera et al., 2005, 2010; Suskauer et al., 2008), and abnormal intrinsic functional connectivity (Tian et al., 2006; Cao et al., 2009; Fair et al., 2012, Kucyi et al., 2015).

\section{DAN}

This study demonstrates that cerebellar regions functionally connected to the DAN are recruited by working memory and attention. Our results align with a rich body of research implicating the cortical DAN in these processes (e.g., Corbetta and Shulman, 2002; Hagler and Sereno, 2006; Szczepanski et al., 2010). How- ever, despite growing evidence for cerebellar contributions to attention and working memory, mention of the cerebellum has been noticeably absent from the DAN literature. On the other hand, resting-state fMRI studies have revealed connectivity between cerebral cortical networks and the cerebellum (Habas et al., 2009; Krienen and Buckner, 2009; O'Reilly et al., 2010; Buckner et al., 2011). Most recently, one member of our team observed that transcranial magnetic stimulation of the cerebellar midline can lead to increases in corticocortical functional connectivity of the DAN, indicating that cerebellar nodes of cortical networks are capable of modulating greater network function (Halko et al., 2014). Until now, the functional relevance of these cerebellar network nodes to task processing has not been established. Our results confirm that cerebellar regions actively contribute to working memory and attentional processing as part of a corticocerebellar attention network.

\section{Outside of VIIb/VIIIa}

Previous work has implicated cerebellar regions beyond lobules VIIb/VIIIa in working memory and attentional functions, namely, lobule VI/Crus I (Allen et al., 1997; Townsend et al., 1999; Chen and Desmond, 2005a, b; Kirschen et al., 2005; Baier et al., 2010; Striemer et al., 2015a, b). Here, group analyses of task activation revealed clusters in lobule VI/Crus I bilaterally; however, only a portion of this activation exhibited functional connectivity with cortical DAN, and the extent was less than half of the size of clusters observed in lobules VIIb/VIIIa. Although this location is consistent with resting-state observations (Buckner et al., 2011), our findings suggest that lobule VI/Crus I activation may reflect recruitment of multiple cerebellar network nodes. However, further investigation is needed uncover the full range of cerebellar contributions to human visual cognition.

\section{The visuomotor cerebellum and ocular-motor vermis}

The role of the cerebellum has long been established in the control of ocular movements, particularly reflexive eye movements, saccades, and smooth pursuit (Voogd et al., 2012). Regions within the cerebellar vermis (lobules VI/VII), Crus I/II, and floccular lobe indirectly receive and send projections to superior parietal eye movement areas and the frontal eye fields (Voogd et al., 2012). Electrical stimulation to these regions in the cerebellum can evoke eye movements (Ron and Robinson, 1973; Fujikado and Noda, 1987). In patients, eye movement deficits arise from lesions in these locations (Baier et al., 2009). In the current study, activation differences were primarily observed in the cerebellar hemispheres, and an analysis of eye movements did not reveal any differences between conditions. Consequently, it is unlikely that the observed cerebellar activation differences can be strongly attributed to cerebellar involvement in ocular control. Furthermore, a recent study directly investigated the relationship between working memory load and eye movements in the cerebellum and found no correlation (Peterburs et al., 2015). Our results suggest that a broader definition of the role of the cerebellum should be assigned and that the regions connected to frontal and parietal attention regions do far more than simply control eye movements.

\section{Cerebellar computation}

Although our results demonstrate that cerebellar subregions are a functional component of the DAN, it is unclear what computation these cerebellar regions perform. Cerebellar cytoarchitecture is remarkably uniform (Bloedel, 1992). Consequently, it has been proposed that the computations performed by the cerebellum are 
similarly invariant across processing domains (Schmahmann, 1991; Ramnani, 2006). As a result, we can look to existing models of motor control in the cerebellum for intuition as to how the cerebellum may contribute to attention and working memory. Some researchers implicate the cerebellum in coding of prediction error (Kawato and Gomi, 1992; Ito, 2001, 2006), whereas others have characterized the cerebellum as an internal timing device (Ivry and Keele, 1989; Bullock et al., 1994; Ivry, 1997). Allowing for both these possibilities, it has been proposed that the cerebellum is critical for the development of internal models (for review, see Ito, 2008). Internal models formed by the cerebellum are thought to facilitate adaptive control necessary for mental activity (Doya 2000; Ito, 2008). The present study cannot distinguish between these possibilities. However, the use of individual subject intrinsic connectivity to identify regions of the cerebellum recruited by working memory and attention lays the groundwork for clarifying the computations the cerebellum performs during working memory and attentional tasks.

In conclusion, the present study characterizes the role of cerebellar lobules VIIb/VIIIa in VWM and attention tasks, and shows that cerebellar regions functionally connected to the DAN, as opposed to other networks, are preferentially recruited during task performance. Typically considered to be the domain of the cortex, the present work suggests that working memory and attentional processes are supported by a dynamic interaction between cortical and cerebellar regions. Taking this into account, we propose a reconsideration of the DAN as a cortical network and suggest it be reconceived as a corticocerebellar attention network.

\section{References}

Allen G, Buxton RB, Wong EC, Courchesne E (1997) Attentional activation of the cerebellum independent of motor involvement. Science 275: 1940-1943. CrossRef Medline

Baier B, Stoeter P, Dieterich M (2009) Anatomical correlates of ocular motor deficits in cerebellar lesions. Brain 132:2114-2124. CrossRef Medline

Baier B, Dieterich M, Stoeter P, Birklein F, Müller NG (2010) Anatomical correlate of impaired covert visual attentional processes in patients with cerebellar Lesions. J Neurosci 30:3770 -3776. CrossRef Medline

Belger A, Puce A, Krystal JH, Gore JC, Goldman-Rakic P, McCarthy G (1998) Dissociation of mnemonic and perceptual processes during spatial and nonspatial working memory using fMRI. Hum Brain Mapp 6: 14-32. CrossRef Medline

Bettencourt KC, Michalka SW, Somers DC (2011) Shared filtering processes link attentional and visual short-term memory capacity limits. J Vis 11:22. CrossRef Medline

Bloedel JR (1992) Functional heterogeneity with structural homogeneity: how does the cerebellum operate? Behav Brain Sci 15:666-678.

Boynton GM, Engel SA, Glover GH, Heeger DJ (1996) Linear systems analysis of functional magnetic resonance imaging in human V1. J Neurosci 16:4207-4221. Medline

Brainard DH (1997) The psychophysics toolbox. Spatial Vision 10:433436. CrossRef Medline

Buckner RL (2013) The cerebellum and cognitive function: 25 years of insight from anatomy and neuroimaging. Neuron 80:807-815. CrossRef Medline

Buckner RL, Krienen FM, Castellanos A, Diaz JC, Yeo BT (2011) The organization of the human cerebellum estimated by intrinsic functional connectivity. J Neurophysiol 106:2322-2345. CrossRef Medline

Bullock D, Fiala JC, Grossberg S (1994) A neural model of timed response learning in the cerebellum. Neural Netw 7:1101-1114. CrossRef Medline

Cao X, Cao Q, Long X, Sun L, Sui M, Zhu C, Zuo X, Zang Y, Wang Y (2009) Abnormal resting-state functional connectivity patterns of the putamen in medication-naive children with attention deficit hyperactivity disorder. Brain Res 1303:195-206. CrossRef Medline

Carp J (2013) Optimizing the order of operations for movement scrubbing: comment on Power et al. Neuroimage 76:436-438. CrossRef Medline

Castellanos FX, Lee PP, Sharp W, Jeffries NO, Greenstein DK, Clasen LS,
Blumenthal JD, James RS, Ebens CL, Walter JM, Zijdenbos A, Evans AC, Giedd JN, Rapoport JL (2002) Developmental trajectories of brain volume abnormalities in children and adolescents with attention-deficit/ hyperactivity disorder. JAMA 288:1740-1748. CrossRef Medline

Chen SH, Desmond JE (2005a) Cerebrocerebellar networks during articulatory rehearsal and verbal working memory tasks. Neuroimage 24: 332-338. CrossRef Medline

Chen SH, Desmond JE (2005b) Temporal dynamics of cerebro-cerebellar network recruitment during a cognitive task. Neuropsychologia 43:12271237. CrossRef Medline

Corbetta M, Shulman GL (2002) Control of goal-directed and stimulusdriven attention in the brain. Nat Rev Neurosci 3:201-215. CrossRef Medline

Courtney SM, Petit L, Maisog JM, Ungerleider LG, Haxby JV (1998) An area specialized for spatial working memory in human frontal cortex. Science 279:1347-1351. CrossRef Medline

Critchley M (1953) The parietal lobes. New York: Hafner.

Dale AM, Fischl B, Sereno MI (1999) Cortical surface-based analysis. Neuroimage 9:179-194. CrossRef Medline

Desmond JE, Gabrieli JD, Wagner AD, Ginier BL, Glover GH (1997) Lobular patterns of cerebellar activation in verbal working-memory and finger-tapping tasks as revealed by functional MRI. J Neurosci 17:9675-9685. Medline

Destrieux C, Fischl B, Dale A, Halgren E (2010) Automatic parcellation of human cortical gyri and sulci using standard anatomical nomenclature. Neuroimage 53:1-15. CrossRef Medline

Diedrichsen J (2006) A spatially unbiased atlas template of the human cerebellum. Neuroimage 33:127-138. CrossRef Medline

Diedrichsen J, Balsters JH, Flavell J, Cussans E, Ramnani N (2009) A probabilistic MR atlas of the human cerebellum. Neuroimage 46:39-46. CrossRef Medline

Dosenbach NU, Fair DA, Miezin FM, Cohen AL, Wenger KK, Dosenbach RA, Fox MD, Snyder AZ, Vincent JL, Raichle ME, Schlaggar BL, Petersen SE (2007) Distinct brain networks for adaptive and stable task control in humans. Proc Natl Acad Sci U S A 104:11073-11078. CrossRef Medline

Doya K (2000) Complementary roles of basal ganglia and cerebellum in learning and motor control. Curr Opin Neurobiol 10:732-739. CrossRef Medline

Fair DA, Nigg JT, Iyer S, Bathula D, Mills KL, Dosenbach NU, Schlaggar BL, Mennes M, Gutman D, Bangaru S, Buitelaar JK, Dickstein DP, Di Martino A, Kennedy DN, Kelly C, Luna B, Schweitzer JB, Velanova K, Wang YF, Mostofsky S, et al. (2012) Distinct neural signatures detected for ADHD subtypes after controlling for micro-movements in resting state functional connectivity MRI data. Front Syst Neurosci 6:80. Medline

Fischl B (2012) FreeSurfer. Neuroimage 62:774-781. CrossRef Medline

Fischl B, van der Kouwe A, Destrieux C, Halgren E, Ségonne F, Salat DH, Busa E, Seidman LJ, Goldstein J, Kennedy D, Caviness V, Makris N, Rosen B, Dale AM (2004) Automatically parcellating the human cerebral cortex. Cereb Cortex 14:11-22. CrossRef Medline

Fox MD, Snyder AZ, Vincent JL, Corbetta M, Van Essen DC, Raichle ME (2005) The human brain is intrinsically organized into dynamic, anticorrelated functional networks. Proc Natl Acad Sci U S A 102:9673-9678. CrossRef Medline

Fujikado T, Noda H (1987) Saccadic eye movements evoked by microstimulation of lobule VII of the cerebellar vermis of macaque monkeys. J Physiol 394:573-594. CrossRef Medline

Fuxman Bass JI, Diallo A, Nelson J, Soto JM, Myers CL, Walhout AJ (2013) Using networks to measure similarity between genes: association index selection. Nat Methods 10:1169-1176. CrossRef Medline

Gao W, Lin W (2012) Frontal parietal control network regulates the anticorrelated default and dorsal attention networks. Hum Brain Mapp 33: 192-202. CrossRef Medline

Glickstein M (2007) What does the cerebellum really do? Curr Biol 17: R824-R827. CrossRef Medline

Goldberg ME, Wurtz RH (1972) Activity of superior colliculus in behaving monkey: II. Effect of attention on neuronal responses. J Neurophysiol 35:560-574. Medline

Gusnard DA, Raichle ME, Raichle ME (2001) Searching for a baseline: functional imaging and the resting human brain. Nat Rev Neurosci 2: 685-694. CrossRef Medline

Habas C, Kamdar N, Nguyen D, Prater K, Beckmann CF, Menon V, Greicius 
MD (2009) Distinct cerebellar contributions to intrinsic connectivity networks. J Neurosci 29:8586-8594. CrossRef Medline

Hagler DJ Jr, Sereno MI (2006) Spatial maps in frontal and prefrontal cortex. Neuroimage 29:567-577. CrossRef Medline

Halko MA, Farzan F, Eldaief MC, Schmahmann JD, Pascual-Leone A (2014) Intermittent theta-burst stimulation of the lateral cerebellum increases functional connectivity of the default Network. J Neurosci 34:12049-12056. CrossRef Medline

Hautzel H, Mottaghy FM, Specht K, Müller HW, Krause BJ (2009) Evidence of a modality-dependent role of the cerebellum in working memory? An fMRI study comparing verbal and abstract n-back tasks. Neuroimage 47:2073-2082. CrossRef Medline

Ikkai A, Curtis CE (2011) Common neural mechanisms supporting spatial working memory, attention and motor intention. Neuropsychologia 49: 1428-1434. CrossRef Medline

Ito M (2001) Cerebellar long-term depression: characterization, signal transduction, and functional roles. Physiol Rev 81:1143-1195. Medline

Ito M (2006) Cerebellar circuitry as a neuronal machine. Prog Neurobiol 78:272-303. CrossRef Medline

Ito M (2008) Control of mental activities by internal models in the cerebellum. Nat Rev Neurosci 9:304-313. CrossRef Medline

Ivry R (1997) Cerebellar timing systems. Int Rev Neurobiol 41:555-573. CrossRef Medline

Ivry RB, Keele SW (1989) Timing functions of the cerebellum. J Cogn Neurosci 1:136-152. CrossRef Medline

Kastner S, Ungerleider LG (2000) Mechanisms of visual attention in the human cortex. Annu Rev Neurosci 23:315-341. CrossRef Medline

Kawato M, Gomi H (1992) A computational model of four regions of the cerebellum based on feedback-error learning. Biol Cybern 68:95-103. CrossRef Medline

Kellermann T, Regenbogen C, De Vos M, Moßnang C, Finkelmeyer A, Habel U (2012) Effective connectivity of the human cerebellum during visual attention. J Neurosci 32:11453-11460. CrossRef Medline

Kelly RM, Strick PL (2003) Cerebellar loops with motor cortex and prefrontal cortex of a nonhuman primate. J Neurosci 23:8432-8444. Medline

Kirschen MP, Chen SH, Schraedley-Desmond P, Desmond JE (2005) Loadand practice-dependent increases in cerebro-cerebellar activation in verbal working memory: an fMRI study. Neuroimage 24:462-472. CrossRef Medline

Krienen FM, Buckner RL (2009) Segregated fronto-cerebellar circuits revealed by intrinsic functional connectivity. Cereb Cortex 19:2485-2497. CrossRef Medline

Kucyi A, Hove MJ, Biederman J, Van Dijk KR, Valera EM (2015) Disrupted functional connectivity of cerebellar default network areas in attentiondeficit/hyperactivity disorder. Hum Brain Mapp 36:3373-3386. CrossRef Medline

Le TH, Pardo JV, Hu X (1998) 4 T-fMRI study of nonspatial shifting of selective attention: cerebellar and parietal contributions. J Neurophysiol 79:1535-1548. Medline

Littell RC, Henry PR, Ammerman CB (1998) Statistical analysis of repeated measures data using SAS procedures. J Anim Sci 76:1216-1231. Medline

Mackie S, Shaw P, Lenroot R, Pierson R, Greenstein DK, Nugent TF 3rd, Sharp WS, Giedd JN, Rapoport JL (2007) Cerebellar development and clinical outcome in attention deficit hyperactivity disorder. Am J Psychiatry 164:647-655. CrossRef Medline

Mesulam MM (1981) A cortical network for directed attention and unilateral neglect. Ann Neurol 10:309-325. CrossRef Medline

Michalka SW, Kong L, Rosen ML, Shinn-Cunningham BG, Somers DC (2015) Short-term memory for space and time flexibly recruit complementary sensory-biased frontal lobe attention networks. Neuron 87: 882-892. CrossRef Medline

O'Reilly JX, Mesulam MM, Nobre AC (2008) The cerebellum predicts the timing of perceptual events. J Neurosci 28:2252-2260. CrossRef Medline

O'Reilly JX, Beckmann CF, Tomassini V, Ramnani N, Johansen-Berg H (2010) Distinct and overlapping functional zones in the cerebellum defined by resting state functional connectivity. Cereb Cortex 20:953-965. CrossRef Medline

Pashler H (1988) Familiarity and visual change detection. Percept Psychophys 44:369-378. CrossRef Medline

Pelli DG (1997) The videotoolbox software for visual psychophysics: transforming numbers into movies. Spatial Vision 10:437-442. CrossRef Medline
Peterburs J, Cheng DT, Desmond JE (2015) The association between eye movements and cerebellar activation in a verbal working memory task. Cereb Cortex. Advance online publication. Retrieved March 29, 2016. doi: 10.1093/cercor/bhv187. CrossRef Medline

Posner MI, Petersen SE (1990) The attention system of the human brain. Annu Rev Neurosci 13:25-42. CrossRef Medline

Power JD, Cohen AL, Nelson SM, Wig GS, Barnes KA, Church JA, Vogel AC, Laumann TO, Miezin FM, Schlaggar BL, Petersen SE (2011) Functional network organization of the human brain. Neuron 72:665-678. CrossRef Medline

Power JD, Barnes KA, Snyder AZ, Schlaggar BL, Petersen SE (2012) Spurious but systematic correlations in functional connectivity MRI networks arise from subject motion. Neuroimage 59:2142-2154. CrossRef Medline

Ptak R, Schnider A (2011) The attention network of the human brain: relating structural damage associated with spatial neglect to functional imaging correlates of spatial attention. Neuropsychologia 49:30633070. CrossRef Medline

Ramnani N (2006) The primate cortico-cerebellar system: anatomy and function. Nat Rev Neurosci 7:511-522. CrossRef Medline

Ron S, Robinson DA (1973) Eye movements evoked by cerebellar stimulation in the alert monkey. J Neurophysiol 36:1004-1022. Medline

Rosen ML, Stern CE, Michalka SW, Devaney KJ, Somers DC (2015) Cognitive control network contributions to memory-guided visual attention. Cereb Cortex. Advance online publication. Retrieved January 14, 2016. doi: 10.1093/cercor/bhv028. CrossRef Medline

Rypma B, D’Esposito M (1999) The roles of prefrontal brain regions in components of working memory: effects of memory load and individual differences. Proc Natl Acad Sci U S A 96:6558-6563. CrossRef Medline

Saalmann YB, Pinsk MA, Wang L, Li X, Kastner S (2012) The pulvinar regulates information transmission between cortical areas based on attention demands. Science 337:753-756. CrossRef Medline

Salmi J, Pallesen KJ, Neuvonen T, Brattico E, Korvenoja A, Salonen O, Carlson S (2010) Cognitive and motor loops of the human cerebrocerebellar system. J Cogn Neurosci 22:2663-2676. CrossRef Medline

Schmahmann JD (1991) An emerging concept: the cerebellar contribution to higher function. Arch Neurol 48:1178-1187. CrossRef Medline

Schmahmann JD (2004) Disorders of the cerebellum: ataxia, dysmetria of thought, and the cerebellar cognitive affective syndrome. J Neuropsychiatry Clin Neurosci 16:367-378. CrossRef Medline

Schmahmann JD, Pandya DN (1997) Anatomic organization of the basilar pontine projections from prefrontal cortices in rhesus monkey. J Neurosci 17:438-458. Medline

Schmahmann JD, Sherman JC (1998) The cerebellar cognitive affective syndrome. Brain 121:561-579. CrossRef Medline

Schweizer TA, Alexander MP, Cusimano M, Stuss DT (2007) Fast and efficient visuotemporal attention requires the cerebellum. Neuropsychologia 45:3068-3074. CrossRef Medline

Setsompop K, Gagoski BA, Polimeni JR, Witzel T, Wedeen VJ, Wald LL (2012) Blipped-controlled aliasing in parallel imaging for simultaneous multislice echo planar imaging with reduced g-factor penalty. Magn Reson Med 67:1210-1224. CrossRef Medline

Sheremata SL, Bettencourt KC, Somers DC (2010) Hemispheric asymmetry in visuotopic posterior parietal cortex emerges with visual short-term memory load. J Neurosci 30:12581-12588. CrossRef Medline

Shulman GL, Fiez JA, Corbetta M, Buckner RL, Miezin FM, Raichle ME, Petersen SE (1997) Common blood flow changes across visual tasks: II. Decreases in cerebral cortex. J Cogn Neurosci 9:648-663. CrossRef Medline

Sprague TC, Serences JT (2013) Attention modulates spatial priority maps in the human occipital, parietal and frontal cortices. Nat Neurosci 16: 1879-1887. CrossRef Medline

Stoodley CJ (2014) Distinct regions of the cerebellum show gray matter decreases in autism, ADHD, and developmental dyslexia. Front Syst Neurosci 8:1647. CrossRef Medline

Stoodley CJ, Valera EM, Schmahmann JD (2010) An fMRI study of intraindividual functional topography in the human cerebellum. Behav Neurol 23:65-79. CrossRef Medline

Stoodley CJ, Valera EM, Schmahmann JD (2012) Functional topography of the cerebellum for motor and cognitive tasks: an fMRI study. Neuroimage 59:1560-1570. CrossRef Medline

Straw AD (2008) Vision egg: an open-source library for realtime visual stimulus generation. Front Neuroinform 2:4. CrossRef Medline

Striemer CL, Cantelmi D, Cusimano MD, Danckert JA, Schweizer TA 
(2015a) Deficits in reflexive covert attention following cerebellar injury. Front Hum Neurosci 9:1-10. CrossRef Medline

Striemer CL, Chouinard PA, Goodale MA, de Ribaupierre S (2015b) Overlapping neural circuits for visual attention and eye movements in the human cerebellum. Neuropsychologia 69:9-21. CrossRef Medline

Suskauer SJ, Simmonds DJ, Fotedar S, Blankner JG, Pekar JJ, Denckla MB, Mostofsky SH (2008) Functional magnetic resonance imaging evidence for abnormalities in response selection in attention deficit hyperactivity disorder: differences in activation associated with response inhibition but not habitual motor response. J Cogn Neurosci 20:478-493. CrossRef Medline

Szczepanski SM, Konen CS, Kastner S (2010) Mechanisms of spatial attention control in frontal and parietal cortex. J Neurosci 30:148-160. CrossRef Medline

Tian L, Jiang T, Wang Y, Zang Y, He Y, Liang M, Sui M, Cao Q, Hu S, Peng M, Zhuo Y (2006) Altered resting-state functional connectivity patterns of anterior cingulate cortex in adolescents with attention deficit hyperactivity disorder. Neurosci Lett 400:39-43. CrossRef Medline

Todd JJ, Marois R (2004) Capacity limit of visual short-term memory in human posterior parietal cortex. Nature 428:751-754. CrossRef Medline

Tomasi D, Chang L, Caparelli EC, Ernst T (2007) Different activation patterns for working memory load and visual attention load. Brain Res 1132: 158-165. CrossRef Medline

Townsend J, Courchesne E, Covington J, Westerfield M, Harris NS, Lyden P, Lowry TP, Press GA (1999) Spatial attention deficits in patients with acquired or developmental cerebellar abnormality. J Neurosci 19:56325643. Medline

Valera EM, Faraone SV, Biederman J, Poldrack RA, Seidman LJ (2005)
Functional neuroanatomy of working memory in adults with attentiondeficit/hyperactivity disorder. Biol Psychiatry 57:439-447. CrossRef Medline

Valera EM, Spencer RM, Zeffiro TA, Makris N, Spencer TJ, Faraone SV, Biederman J, Seidman LJ (2010) Neural substrates of impaired sensorimotor timing in adult attention-deficit/hyperactivity disorder. Biol Psychiatry 68:359-367. CrossRef Medline

Van Dijk KR, Hedden T, Venkataraman A, Evans KC, Lazar SW, Buckner RL (2010) Intrinsic functional connectivity as a tool for human connectomics: theory, properties, and optimization. J Neurophysiol 103:297-321. CrossRef Medline

Vogel EK, Machizawa MG (2004) Neural activity predicts individual differences in visual working memory capacity. Nature 428:748-751. CrossRef Medline

Voogd J, Schraa-Tam CK, van der Geest JN, De Zeeuw CI (2012) Visuomotor cerebellum in human and nonhuman primates. Cerebellum 11:392-410. CrossRef Medline

West BT, Welch KB, Galecki AT (2014) Linear mixed models. Boca Raton, FL: CRC.

Xu Y, Chun MM (2006) Dissociable neural mechanisms supporting visual short-term memory for objects. Nature 440:91-95. CrossRef Medline

Yeo BT, Krienen FM, Sepulcre J, Sabuncu MR, Lashkari D, Hollinshead M, Roffman JL, Smoller JW, Zöllei L, Polimeni JR, Fischl B, Liu H, Buckner RL (2011) The organization of the human cerebral cortex estimated by intrinsic functional connectivity. J Neurophysiol 106: 1125-1165. CrossRef Medline 